\title{
Enterprise-wide Information Logistics: Conceptual Foundations, Technology Enablers, and Management Challenges
}

\author{
Robert Winter \\ Institute of Information Management, University of St. Gallen \\ Mueller-Friedberg-Strasse 8, 9000 St. Gallen, Switzerland \\ Robert.Winter@unisg.ch
}

\begin{abstract}
Information logistics (IL) is understood as the process of planning, implementing and controlling cross-unit data flows as well as storage and provisioning of respective data - as long as data is used for unit's decision support. IL creates significant business value - but mostly for other units and in the future while costs occur now at the IT units. As a consequence, managerial aspects of IL like requirements analysis, strategic alignment, financials, organizational design and architecture design need more attention than technical issues. This article defines $I L$, discusses its managerial challenges, and sketches first solutions.
\end{abstract}

Keywords. Information Logistics, Information Management

\section{Introduction}

A great number of studies prove the unchallenged high relevance of business intelligence (BI) and data warehousing (DWH) [3, 29, 38]. Analytical information systems meanwhile represent an essential component of the enterprise application landscape and claim a considerable share of the IT budget. Organizations however are no longer primarily concerned with establishing analytical information systems. They rather face the challenge of continuously operating and further developing these systems according to changing business requirements and new potentials of IT innovations. In this regard, two crucial aspects are still widely neglected: firstly, a comprehensive view on the entirety of BI/DWH initiatives does not yet supersede a focused partial or project-specific view. Secondly, neither the long investment cycles nor the infrastructure character of such systems is adequately considered.

Concepts like DWH and BI enable a sustainable value creation by providing a systematic, cross-functional consolidation and exploitation of information. While technical aspects like standardization and integration project management matured during the 15 years of $\mathrm{DWH} / \mathrm{BI}$, organizational and economic challenges still need to be addressed. As a conceptual foundation, the term 'information logistics' is introduced, and technology enablers are specified in Section 2. The conceptual characteristics of information logistics are discussed in Section 3. Section 4 summarizes the managerial challenges of information logistics and sketches solution approaches. Section 5 is a short summary and outlook to future research in this field.

\section{The Information Logistics Concept}

If we abstract from information supply differentiations which result from different technologies (data warehouse systems, data marts, OLAP etc.) and focus on the conceptual perspective, information logistics can be defined as follows: Information logistics (IL) comprises the planning, control, and implementation of the entirety of cross-unit data flows as well as the storage and provisioning of such data.

In order to differentiate IL and operational data integration, only those data flows are considered to be IL components which support decision making. If data is used for decision making in the same unit where it originates, such flows do not fall under our IL definition because in this case, most of the managerial challenges to not occur.

\subsection{Cross-unit Data Flows}

'Cross-unit' refers to units of arbitrary size. Being the finest granularity of organizational structure, i.e. the smallest autonomously acting entity of an organization [10, 18], 'job' constitutes the smallest possible unit. On a detailed level of analysis, cross-job data flows in a small organization can be considered as IL components because data originating from one part of the organization are used in another part.

For larger organizations and a more aggregate analysis, 'business unit' is suitable. The entirety of data flows across business units then is considered to be the subject of IL - including the storage and provisioning of such data. Since only 
data flows for decision support fall under our definition, operational data integration (e.g. using EAI systems) is not relevant in this context.

The biggest reference unit is represented by the company as a whole. Thus, information lo- gistics also comprises cross-company data flows as required in inter-organizational co-operations or when outsourcing business processes [28, 35].

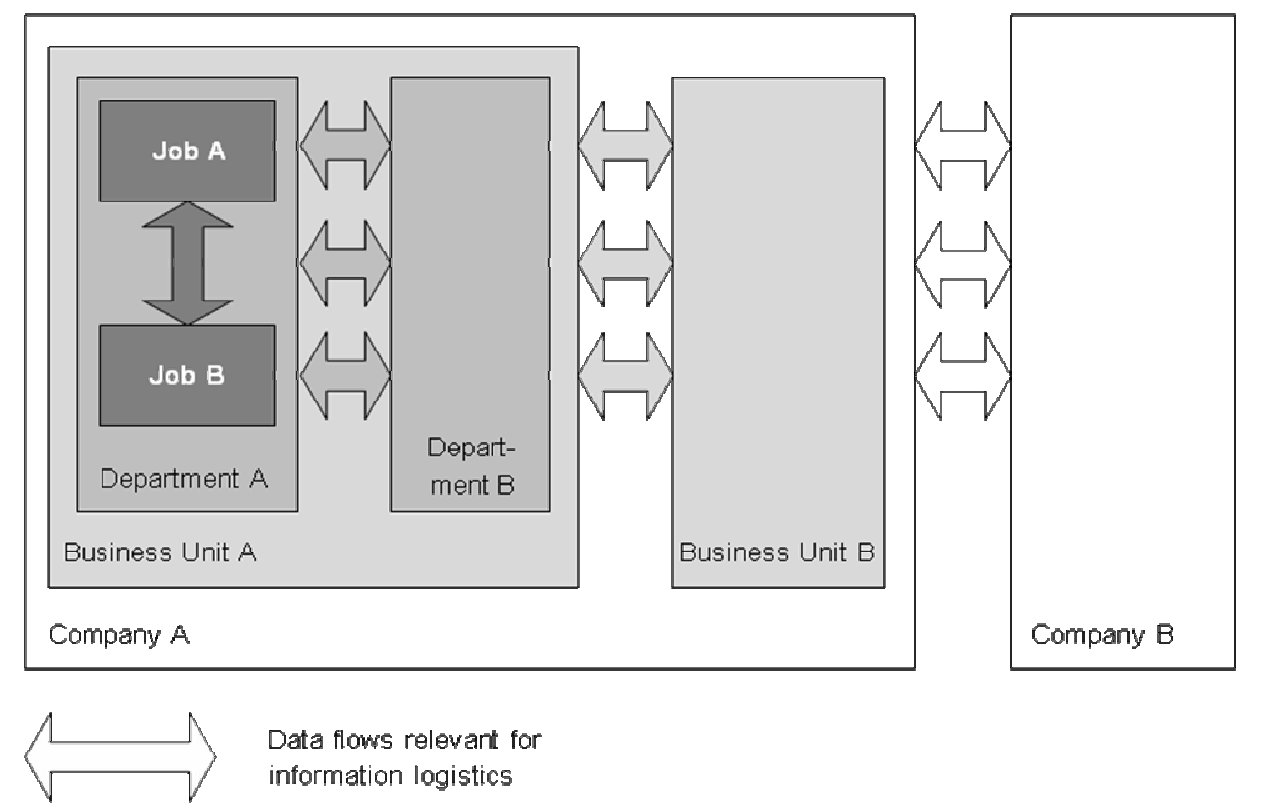

Figure 1. Different Notions of Information Logistics

Figure 1 illustrates the various levels of analysis which imply whether a data flows is considered as cross-unit data flow (and hence is a IL component) or not. Jobs, departments, business units and companies are illustrated in different grey tones. For every level of a unit (and respective grey tone), the data flows which are relevant for the respective IL understanding are tinted in the same grey tone. Department-wide IL is comprised of all cross-job (dark grey) data flows in that department. Business unit-wide IL is comprised of all cross-department data flows in that business unit. Enterprise-wide IL is comprised of all cross-department data flows in that company. Inter-Organizational IL is comprised of all crosscompany data flows in a company network.

\subsection{Different Levels of Analysis}

By means of IL, data generated in one unit is made available for analytical processing by another unit. As a consequence, data flows within any unit are not considered as IL components. However, such 'internal' data flows can absolutely be a IL component on a different level of analysis: if the objects under consideration are corporate divisions, division-internal data flows are not IL components - but if the objects under consideration are departments within a division, cross-departmental data flows become relevant although they are division-internal. Which data flows are considered IL components, therefore depends on the aggregation level and on the scope of analysis.

The term 'analytical utilization' adverts to the usage of information as a means for decision support. A decision represents an - in the context of IL always conscious - choice between two or more alternatives of action [39]. Information constitutes the basis for such choices [35]. Data turns into information when it is interpreted by a decision maker in a certain context [22]. Hence data flows do not intrinsically constitute information flows. Because of the application neutral nature of data, its context is only finally determined with its actual usage [26].

IL aims at supplying information for all kinds of decisions in an organization. On the one hand, decisions are supported on different hierarchy levels of a company (strategic decision making, management control and operative control). On the other hand, decisions differ regarding their degree of structuring (unstructured, semistructured, structured) $[16,30]$. IL is not limited to the support of certain process types. In fact IL serves planning as well as operational processes. The supply of planning processes with aggre- 
gated data - a classical application of BI tools represents a planning utilization of IL. Likewise conceivable is the supply of operational processes with detailed data, e.g. the timely provision of customer information in order to support pricing in sales processes.

IL thus addresses all kinds of information supply for decision making. Only data flows serving operational purposes without decision consequences, e.g. the flow of order data from the order entry to picking, are not considered as IL components even if they go across organizational units.

\subsection{Functional View of Information Logis- tics}

The functional view of IL can be directly derived from its definition: In analogy to the definition of logistics as planning, controlling and implementing material flows internal and external to the organization $[9,12,36]$, IL is comprised of data flow planning, data flow scheduling, and data flow implementation. In addition, the IL definition implies storing and provisioning data to be a part of IL.

On a strategy level, outputs and goals for these functions need to be identified. On an organizational level, respective processes, organizational structures and conceptual models need to be defined. Such conceptual designs are then implemented using IT systems like data bases, extraction and transformation systems, analysis tools, etc.

The general objective of IL is to provide decision support by supplying relevant data of adequate quality, even if the required data originates in different units. Thereby IL considerably contributes to the realization of synergies.

\subsection{Information Logistics vs. Data Ware- housing, Business Intelligence, and Management Support System}

\section{Information Logistics vs. Data Warehousing}

Based on William Inmon's original definition of the data warehouse as "a subject-oriented, integrated, non-volatile, and time-variant collection of data in support of management's decisions" [20], the understanding of data warehousing has broadened during recent years and is moving towards our IL understanding. Data warehousing comprises the entirety of processes and systems for the operations and utilization of a data warehouse information system [27, 31]. The data warehouse (or more precisely the data warehouse information system) serves as a central, enterprise-wide platform, separated from operational databases, which integrates data from operational systems for being used by analytical applications $[19,21]$. The deployment of data warehousing is expanding from pure decision support (as proposed by Inmon) to more operational applications as for instance in marketing $[4,26]$. However, the prevalent focus on data warehouse information systems [see e.g. 6] is only rarely extended by including strategic or organizational issues [see e.g. 24, 32].

Furthermore, the DWH discussion focuses on integrated storage using a central database $[7,20$, 25], while IL aims at planning, directing, and controlling data flows.

The essential differences between data warehousing and IL can be summarized as follows:

- In contrast to data warehousing, IL exhibits a broader focus that does not only emphasize the information system, but rather examines the strategy, organization and information system at large.

- Data warehousing focuses on the generation of an integrated database, whereas IL targets the management of information flows for the fulfillment of information needs.

- The focus of data warehousing is typically intra-corporate, whilst IL considers interorganizational data flows as well.

Information Logistics vs. Business Intelligence The definition of business intelligence (BI) is more blurry than the one of data warehousing which hampers a distinct delimitation. Its original meaning is shaped by the following Gartner definition "Data analysis, reporting, and query tools can help business users wade through a sea of data to synthesize valuable information from it - today these tools collectively fall into a category called 'Business Intelligence'" [1]. BI was originally used as a collective term for different analytical applications which access the data warehouse as well as related technologies for data analysis [23, 30]. Alongside a variety of other notions of the term exists [4]. On the one hand, system-centered expanded notions subsume the entirety of analytical systems as well as the feeding databases / data warehouses under the term BI $[33,40]$. On the other hand, holistic approaches define BI as the entirety of systems 
and processes required for the analysis of the environment $[5,14,17]$.

The narrower understanding of $\mathrm{BI}$ as the entirety of analytical systems [40] can easily be distinguished from IL, since IL offers a considerably more comprehensive and holistic view. However, the broader the comprehension of BI, the blurrier the differentiation to IL becomes. Once again the emphasis on data flows represents the main delimitation criterion. Furthermore, none of the definitions of BI comprises inter-organizational data flows explicitly. BI is usually not understood as an inter-organizational concept, although external data sources can be employed.

\section{Information Logistics vs. Management Sup- port Systems}

The concept of Management Support Systems (MSS) is used as a collective term for different kinds of analytical systems [8]. Management Information Systems (MIS), Decision Support Systems (DSS) and Executive Information Systems (EIS) whose development partially goes back to the 1970's constitute different MSS classes. In the context of modern IL / BI concepts [15], those terms represent specific systems concepts.

MIS indicate systems that supply the middle management with reports supporting everyday structured decision making. Those reports are based on enterprise data derived from operational systems. The data is partially historicized and typically possesses a close subject reference [11, $30,34]$. Furthermore the term MIS is partially employed as a synonym for MSS. DSS in turn represent systems that are based on in-depth, problem specific data analysis models and databases. DSS interactively support knowledge makers in semi-structured decisions [11, 30, 34]. Sometimes OLAP and data mining tools are also ranked among these [30]. Expert systems represent related systems that automatically reach decisions in narrowly delimited subject areas reverting on a knowledge base and artificial intelligence methods $[13,30]$. Finally, EIS are systems that primarily support the top management in making (usually unstructured) strategic decisions. Functions of an EIS include amongst others the aggregation and integration of data from existing MIS, DSS, and external sources, the investigation in different data sources, visualization and communication tasks [15, 30, 34].

In summary, MSS constitute a subset of IL. They comprise different classes of analytical systems which are part of IL implementation. The literature on MSS clearly reveals the historical context - on the one hand, data integration is not an objective of MSS like it is within data warehousing. On the other hand, MSS merely focus on the different managerial levels of an organization and neglect operational aspects. Moreover, recent literature predominantly addresses IT systems and does not sufficiently take into account organizational and strategic considerations.

\subsection{Synergy Potentials of Information Logistics}

Synergies are achieved if the output of a group is better than the output of the best group member as well as better than each combination of the reclusively generated output [37]. In an organizational context, synergies are created if the output of one organizational unit can be used as intermediate input for another or if organizational units bundle their competences and thereby reduce costs or create added value [30]. Particularly the bundling of products, the combination of competencies and the integration of (e.g. customer) knowledge demands for data transfers between organizational units - this is the 'business case' (i.e. economic justification) for IL.

Specialization and division of labor as well as function-specific information systems led to a distributed and fragmented storage of corporate data in the early times of computing. An efficient and effective fulfillment of information needs, which represents the major objective of IL, therefore often requires the inclusion of external information [26]. The source of information may either be located inside or outside the organization.

If synergies are actually realized, the overall added value is in fact higher than the sum of added values of each of the contributors. This does however not imply that the supply of local data is always beneficial for the supplying unit. The extent of synergetic effects can potentially be irregularly distributed among the contributing and utilizing units. It may thus occur that one organizational unit produces high quality data with a huge effort which is then gratefully used by another unit. A holistic concept for IL design and operations needs to consider these effects and provide adequate control and incentive systems. 


\section{Characteristics of Information Logistics}

As a business support concept, IL is characterized by four properties: It is a cross-unit infrastructure (in contrast to unit-specific business support systems), its horizon and scope are strategic (in contrast to most IT support systems), it has process character (in contrast to data-centric IT support systems), and its innovation cycles are driven by IT enablers (in contrast to businessdriven support systems). These properties are examined in the following section.

\subsection{Infrastructure Character}

Besides processes which affect data and data utilization, IL operations demand for a multitude of other processes. As a concept which focuses on synergies and which transcends organizational units, IL also suggests to contemplate these processes in their entirety. Therefore, it is advisable to embed these processes within a common infrastructure platform. The corresponding infrastructure topics are crossfunctional. In line with the transcending character of IL, these cross-functional issues affect various domains of data warehousing and related systems. Usually, they are not restricted to particular domains or projects. Infrastructure is essential for successful IL.

Infrastructure provides the necessary organizational and technical requirements for information systems. It is open to use, reusable, and is provided in the form of standardized, reliable services, which can be used by multiple infrastructure applications [26]. Frequently, the benefits of infrastructure are hardly quantifiable, so that corresponding investments call for strategic management decisions. On the other hand, the utilization potentials may not be quantifiable because future usages and respective addedvalues are unknown.

The infrastructure notion goes beyond mere system operations, and in fact incorporates all those basic facilities that are required for the realization and operations of business applications in IL. Infrastructure does not solely comprise hardware and software, but also includes processes and process knowledge, which are necessary for planning, controlling, maintaining, and supporting the infrastructure. Likewise, standards and principles are required for the infrastructure, which enable efficient operations and a trouble-free interaction of components. Clearly defined interfaces need to regulate the interaction of infrastructure components as well as the access of business applications to the infrastructure.

The following explanations only address strategic and organizational infrastructure aspects technological aspects are neglected.

In IL, the following topics exhibit an infrastructure character according to the definition given above:

- Architecture management

- Metadata management

- (Data) Quality management

- Master data management

- Management of privacy and data security

- Operational and organizational structure (including service management and service accounting)

- Project management and requirements management

All topics listed above are not only relevant for IL, but also impact enterprise-wide information management. Accordingly, in the context of IL it has to be decided if enterprise-wide standards and solutions are to be established or if concepts applied in the domain of operational systems are to be used. Usually, an isolated approach and a separate installation of an infrastructure for IL is not recommendable as IL must be closely embedded in the enterprise-wide IT landscape and needs to access existing infrastructure directly as well as indirectly (i.e. by referencing data from operational systems or by using master and meta data). Furthermore, the realization of potential economies of scale has to be examined.

\subsection{Strategic Character}

Decisions affecting holistic relations and having long-term characteristics, are denoted "strategic" [2]. In accordance to its definition, IL is crossfunctional, and the usage benefits of IL tend to be long-term. Therefore, IL is strictly strategic, and has to be planned, operated, and managed accordingly. This means that those organizational units which have comprehensive responsibility should be in charge of IL. Furthermore, profitability decisions must take into account that IL investments usually do not pay off in common terms (two to three years).

\subsection{Process Character}

The definition of IL is intentionally not restricted to the formerly data centric view of data ware- 
housing. In fact, this understanding also addresses applications which embed techniques and procedures of data analysis and information supply in the context of process execution. The usage of analytical data is increasingly integrated into operational processes, so that operational decisions benefit from the data basis supplied by IL, too. The overall aim is to boost the effectiveness and efficiency of business processes.

\subsection{IT as an Enabler for Information Logistics}

IT support systems are usually driven by specific business requirements. Since IL is crossfunctional by definition, functional IL requirements - if being specified at all - are oriented much more at corporate goals (e.g. realization of synergies) than at specific business requirements. As a consequence, IT innovations play a more important role for the continuing development of IL than they do for IT support systems in general. Corporate IL was driven by the innovative concepts of data warehouse information systems, ETL tools, operational data stores, data marts and BI tools in the past. Major future innovations will also be associated with IT innovations.

\section{Managerial Challenges of Information Logistics}

The specifics of IL imply specific managerial challenges. In practice, a discrepancy can be observed: On the one hand, IL topics attract high attention and are classified as very important. On the other hand, isolated, local solutions and short-term initiatives are common. Accordingly, the implementation of infrastructure activities has to take into account various challenges.

\subsection{Risks}

Risk factors include project size and complexity. The more comprehensive the definition of infrastructure topics, the more dependencies and (partly conflicting) requirements need to be covered, and the higher is the coordination effort among involved organizational units. These obstacles form a trade-off with the effort of creating synergies by fostering broad adoption of infrastructure topics across the organization. Solutions for this problem can be taken from best practices of data warehousing projects, e.g. the decomposition of the project into sequentially implemented subprojects and modules. The initial project phases must focus on quick wins in order to demonstrate the value proposition of infrastructure activities to the units. In this context, unrealistic expectations must be mitigated. These can be caused by a lack of insight and understanding of the project complexity. Despite the intended reduction of complexity, it should be kept in mind, that the specific infrastructure topics cannot be addressed in isolation. For example, the areas of meta data management, master data management, and data quality management show considerable overlap. Therefore, respective activities need to be coordinated.

\subsection{Joint Usage}

Infrastructure is used jointly by multiple applications. On the one hand, this enables economies of scale; on the other hand, this complicates the allocation of infrastructure costs to particular user groups. The benefits of infrastructure cannot easily be quantified. It is clear that infrastructure is useful for IL applications, but it is not clear to what exact extent infrastructure accounts for added value. Often, there is no awareness that IL infrastructure topics need to be managed similarly to other infrastructure activities (e.g. investments in hardware). Investments need to be made despite missing or incomplete evidence of profitability. Furthermore, use cases which demonstrate the benefit must be presented. Closely related to these problems is the challenge of enlisting (upper) management support for infrastructure projects. Sponsorship by appropriate members of management is required due to high costs for implementation and long term nature of the projects. This support can be solely monetary, but also in terms of advocacy or sponsorship.

\subsection{Holistic View vs. Partial Views}

Frequently, infrastructure projects end up in halffinished or local solutions which cannot create the projected benefits. The limited view of the involved organizational units constitutes a considerable risk factor. Every unit predominantly strives to reach its local optimum, i.e. to achieve local objectives with minimal effort. This leads to preferences for certain established tools and solution providers. Existing infrastructure solutions of adjacent units are widely disregarded. Those developments must be counteracted with a comprehensive resource management and a clear 
communication of the advantages of an overall IL infrastructure.

\subsection{Architecture Alignment}

The fact that IL and associated infrastructure elements have to be embedded into the enterprise-wide IT architecture has already been mentioned. A harmonization of organizational structures aims for a seamless integration of IL and its infrastructure into the IT organization. Ideally, the IL design follows the same criteria that apply for the operational IT architecture. Stakeholders, ownerships, responsibilities and processes have to be defined in exactly the same manner as those for IT as a whole. Another objective is an integrated architecture management that defines architecture governance from a central perspective. It does not only cover IL, but also the corporate IS/IT architecture as a whole. The architecture unit controls the development of platforms and new applications. It thereby assures that the same weight is given to the enterprise view as the partial views of the individual units. The overall perspective does not only cover single projects, but in fact complete value chains with their respective processes. This facilitates avoiding redundancies and supports identifying synergy potentials.

\section{Summary and Outlook}

An effective and efficient data supply for decision support is a critical success factor in today's highly competitive business environment. In complex organizations and business networks, cross-unit data flows become more important. Although decentralization and specialization lead to desirable behavior in most aspects, a completely decentralized data supply would not be able to cover all information needs. An infrastructure is needed which enables the planning, control and implementation of cross-unit data flows in order to realize enterprise-wide (or even inter-organizational) synergies. While much progress has been made in the last 25 years in regard of IT support systems for IL, many managerial issues need to be addressed. IL is different from traditional, unit-specific information systems and need specific methods for defining goals and services, specifying appropriate processes and organizational structures, and running such an infrastructure in a sustained way. This includes the adaptation of IT infrastructure service management standards, the development of appropriate financing and charging schemes, the standardization of IL product / service catalogues, the proposition of reference planning / controlling / operations processes for the most important IL scenarios, and a more comprehensive understanding of the economics of infrastructure utilization in decentralized organizations.

\section{Acknowledgements}

The material presented here has initially been prepared together with Moritz Schmaltz, Barbara Dinter and Tobias Bucher as an introduction to the book "Integrierte Informationslogistik" (Dinter, Barbara, Winter, Robert, eds.) published 2008 by Springer in German. Anne Cleven helped to transform the material for an international audience.

\section{References}

[1] M. Anandarajan, A. Anandarajan, and C. A. Srinivasan, Business Intelligence Techniques - A Perspective from Accounting and Finance. Berlin: Springer, 2003.

[2] R. Anthony, Planning and Control Systems: A Framework for Analysis. Boston: Harvard University Press, 1965.

[3] D. Arnott and G. Pervan, "Eight key issues for the decision support systems discipline," Decision Support Systems, vol. 44, pp. 657672, 2008.

[4] B. Azvine, Z. Cui, and D. D. Nauck, "Towards real-time business intelligence," $B T$ Technology Journal, vol. 23, pp. 214-225, 2005.

[5] T. Bucher and B. Dinter, "Process Orientation of Information Logistics - An Empirical Analysis to Assess Benefits, Design Factors, and Realization Approaches," presented at 41 th Hawaii International Conference on System Sciences (HICSS-41), Waikoloa, Big Island, Hawaii, 2008.

[6] P. Chamoni and P. Gluchowski, "Analytische Informationssysteme - Business Intelligence-Technologien und -Anwendungen," 3 ed. Berlin et al.: Springer, 2006.

[7] S. Chaudhuri and U. Dayal, "An overview of data warehousing and OLAP technology," ACM SIGMOD Record, vol. 26, pp. 65-74, 1997.

[8] T. D. Clark, M. C. Jones, and C. P. Armstrong, "The Dynamic Structure of Management Support Systems: Theory Devel- 
opment, Research Focus, and Direction," MIS Quarterly, vol. 31, pp. 579-615, 2007.

[9] J. J. Coyle, E. J. Bardi, and C. J. Langley, The Management of Business Logistics, 5 ed. St. Paul: West Publishing Company, 1992.

[10]R. L. Daft, Organization. Theory and Design. Cincinnati: South-Western College Publishing, 1998.

[11] G. B. Davis and M. H. Olson, Management Information Systems - Conceptual Foundations, Structure and Development, 2 ed. New York: McGraw-Hill Book Company, 1985.

[12] J. M. Deepen, Logistics outsourcing relationships. Heidelberg: Physica-Verlag, 2007.

[13] Y. Duan, J. S. Edwards, and M. X. Xu, "Web-based expert systems: benefits and challenges," Decision Support Systems, vol. 42, pp. 799-811, 2005.

[14] Gartner Group, "The Gartner Glossary of Information Technology Acronyms and Terms," 2004.

[15]P. Gluchowski and H.-G. Kemper, "Quo Vadis Business Intelligence?," BI-Spektrum, vol. 1, pp. 12-19, 2006.

[16] A. Gorry and M. Scott Morton, "A Framework for Management Information Systems," Sloan Management Review, vol. 13, pp. 55-70, 1971.

[17] M. Grothe and P. Gentsch, Business Intelligence, 1 ed. München: Addison-Wesley, 2000.

[18] R. H. Hall, Organizations. Structures, Processes and Outcomes, 6 ed. New Jersey: Prentice Hall, 1996.

[19]Z. Huang, L.-d. Chen, and M. N. Frolick, "Integrating Web-Based Data into a Data Warehouse," Information Systems Management, vol. 19, pp. 23-34, 2002.

[20] W. H. Inmon, Building the Data Warehouse, 3 ed. New York: Wiley Computer Publishing, 2002.

[21]M. A. Jeusfeld, "Special Issue on Design and Management of Data Warehouses," International Journal of Cooperative Information Systems, vol. 10, pp. 235-236, 2001.

[22]R. Jung, Architekturen zur Datenintegration: Gestaltungsempfehlungen auf der Basis fachkonzeptueller Anforderungen, 1 ed. Wiesbaden: Deutscher Universitätsverlag, 2006.

[23] R. Jung and R. Winter, "Data Warehousing: Nutzungsaspekte, Referenzarchitektur und Vorgehensmodell," in Data Warehousing
Strategie, R. Jung and R. Winter, Eds. Berlin etc.: Springer, 2000, pp. 3-20.

[24]R. Kachur, Data Warehouse Management Handbook. USA: Prentice Hall, 2000.

[25]R. Kimball, L. Reeves, M. Ross, and W. Thornthwaite, The Data Warehouse Lifecycle Toolkit: Expert Methods for Designing, Developing and Deploying Data Warehouses. Chichester: Wiley, 1998.

[26] M. Klesse, "Leistungsverrechnung im Data Warehousing - Entwicklung einer Methode." St. Gallen: Universität St. Gallen, 2007.

[27] M. Klesse and R. Winter, "Organizational Forms of Data Warehousing: An Explorative Analysis," presented at 40th Hawaii International Conference on System Sciences (HICSS-40), Los Alamitos, 2007.

[28] V. S. Lai and W. Chung, "Managing International Data Communications," Communications Of The Association For Information Systems, vol. 45, pp. 89-93, 2002.

[29] J. Laudon and K. Laudon, Management Information Systems: Managing the Digital Firm, 10 ed: Prentice Hall, 2006.

[30] K. C. Laudon, J. P. Laudon, and D. Schoder, Wirtschaftsinformatik: Eine Einführung. München et al.: Pearson Studium, 2006.

[31] S. T. March and A. R. Hevner, "Integrated decision support systems: A data warehousing perspective," Decision Support Systems, vol. 43, pp. 1031- 1043, 2007.

[32] McKnight, "Effective Data Warehouse Organizational Roles and Responsibilities," McKnight Associates, Inc., White Paper 2000.

[33] S. Negash, "Business Intelligence," Сотmunications Of The Association For Information Systems, vol. 2004, pp. 177-195, 2004.

[34] J. A. O'Brien, Management Information Systems - Managing Information Technology in the Networked Enterprise, 3 ed. Chicago: Irwin, 1996.

[35] A. Picot, R. Reichwald, and R. T. Wigand, Die grenzenlose Unternehmung: Information, Organisation und Management, 5 ed. Wiesbaden: Gabler, 2003.

[36]D. Simchi-Levi, The logic of logistics : theory, algorithms, and applications for logistics and supply chain management, 2 ed. New York: Springer Science+Business Media, 2005.

[37] S. Stumpf, "Wann man von Synergie in Gruppen sprechen kann: Eine Begriffsana- 
lyse," Gruppendynamik, vol. 30, pp. 191206, 1999.

[38] H. J. Watson, D. L. Goodhue, and B. H. Wixom, "The benefits of data warehousing: why some organizations realize exceptional payoffs," Information \& Management, vol. 39, pp. 491-502, 2002.

[39] G. Wöhe, Einführung in die Allgemeine Betriebswirtschaftslehre, 18 ed. München: Vahlen, 1993.

[40] L. Wu, G. Barash, and C. Bartolini, "A Service-oriented Architecture for Business Intelligence," presented at IEEE International Conference on Service-Oriented Computing and Applications(SOCA'07), Newport Beach, 2007. 